\title{
Study design and protocol for moving forward: a weight loss intervention trial for African-American breast cancer survivors
}

\author{
Melinda R. Stolley ${ }^{1,2^{*}}$, Lisa K. Sharp ${ }^{2,3}$, Giamila Fantuzzi ${ }^{4}$, Claudia Arroyo ${ }^{1}$, Patricia Sheean ${ }^{5}$, Linda Schiffer ${ }^{1}$,
} Richard Campbell ${ }^{2}$ and Ben Gerber ${ }^{1,2}$

\begin{abstract}
Background: Breast cancer survival rates are significantly lower among African-American women compared to white women. In addition, African-American women with breast cancer are more likely than white women to die from co-morbid conditions. Obesity is common among African-American women, and it contributes to breast cancer progression and the development and exacerbation of many weight-related conditions. Intervening upon obesity may decrease breast cancer and all-cause mortality among African-American breast cancer survivors.

Methods/Design: Moving Forward is a weight loss intervention being evaluated in a randomized trial with a projected sample of 240 African American breast cancer survivors. Outcomes include body mass index, body composition, waist:hip ratio, and behavioral, psychosocial and physiological measures. Survivors are randomized to either a 6-month guided weight loss intervention that involves twice weekly classes and text messaging or a selfguided weight loss intervention based on the same materials offered in the guided program. The guided intervention is being conducted in partnership with the Chicago Park District at park facilities in predominantly African-American neighborhoods in Chicago. Recruitment strategies include direct contact to women identified in hospital cancer registries, as well as community-based efforts. Data collection occurs at baseline, post-intervention (6 months) and at a 12-month follow-up.
\end{abstract}

Discussion: This study evaluates a community-based, guided lifestyle intervention designed to improve the health of African-American breast cancer survivors. Few studies have addressed behavioral interventions in this high-risk population. If successful, the intervention may help reduce the risk for breast cancer recurrence, secondary cancers, and co-morbid conditions, as well as improve quality of life.

Trial registration: U.S. Clinicaltrials.gov number: NCT02482506, April 2015

Keywords: Breast cancer, Weight loss, African-American, Survivorship

\section{Background}

Breast cancer is the second leading cause of cancer death among African-American women [1]. Despite lower incidence, breast cancer mortality rates for black women are higher than those for women of other racial/ ethnic groups even after controlling for age, socioeconomic status, tumor stage and histology, hormone

\footnotetext{
*Correspondence: mstolley@mcw.edu

${ }^{1}$ Cancer Center and Department of Medicine, Medical College of Wisconsin, 8701 Watertown Plank Road, Milwaukee, WI 53226-3548, USA

${ }^{2}$ Institute for Health Research and Policy, University of Illinois at Chicago

(UIC), Chicago, IL, USA

Full list of author information is available at the end of the article
}

receptor status, and menopausal status ([2, 3], http:// www.seer.cancer.gov/). Ninety- two percent of white women will survive for at least five years after diagnosis, compared to only $77 \%$ of black women [4]. Additionally, African-American women with breast cancer are more likely to die from co-morbid conditions, including diabetes and hypertension $[5,6]$. These disparities are not easily explained and involve multiple issues related to social determinants of health [7]. However, obesity and behavioral factors are likely additional and related contributors. 
Obesity contributes to breast cancer progression, as well as the development and exacerbation of many comorbid conditions [8-13]. This relationship remains after adjusting for stage at diagnosis, nodal status, treatment type, and menopausal status prior to diagnosis $[8,14-16]$. Obesity is hypothesized to promote tumor progression by (1) producing higher concentrations of estrogen and testosterone $[2,17,18],(2)$ contributing to insulin resistance, leading to increased levels of insulinlike growth factor-I (IGF-1) and insulin-like growth factor-binding protein-3 (IGFBP-3) [10, 19, 20], and (3) contributing to chronic inflammation [21]. This paper describes the study protocol for Moving Forward: A weight loss program for African-American breast cancer survivors.

Eighty-two percent of African-American women are overweight or obese [22] and many have dietary and physical activity patterns that contribute to obesity, cancer and other health risks [11, 23-26]. Among breast cancer survivors, baseline dietary data from the Women's Healthy Eating and Living Study showed that African-American survivors $(N=118)$ consumed significantly more calories from fat and less fruit than Asians or whites, and they were less likely than other women to meet guidelines for physical activity [27]. Findings from a survey of 468 African-American breast cancer survivors documented that most did not exercise regularly, and median television viewing was over $5 \mathrm{~h}$ daily [28]. The combined effects of obesity, unhealthy diet and inactivity may contribute to the disparity in breast cancer survival among African-American women and may be the easiest modifiable factors to address in the near term $[12,29]$.

Several weight loss interventions report beneficial results for breast cancer survivors, including weight loss [30-34], prevention of weight gain [35], improved body composition and lipids $[33,36]$, decreases in sex hormones [36], decreases in dietary fat intake [35], increases in fruit, vegetable and/or fiber intake [35], increased physical activity [30, 35] and improved psychological status [35]. Inclusion of African-American women in these trials was limited. Considering the high rates of breast cancer and all-cause mortality, co-morbidities, and obesity, weight loss is an important goal. However, due to a complex interaction of behavioral, cultural and societal factors, AfricanAmerican women are less likely to participate in traditional weight loss programs, more apt to drop out, and lose less weight than white women [37, 38].

Recent efforts support the feasibility of weight loss interventions for African-American breast cancer survivors [31, 39, 40] However, studies were not fully powered and none examined the physiological impact of weight loss for African-American breast cancer survivors.
Weight loss trials with white breast cancer survivors support the positive impact of weight loss on intermediate markers of breast cancer including sex hormones (estrogen, estradiol, testosterone, sex hormone binding globulin), chronic inflammation (C-reactive protein [CRP], interleukin-6 [IL-6], and TNF- $\alpha$ ), and hyperinsulinemia (nsulin-like growth factor-1 [IGF-1], insulin-like growth binding protein-3 [IGBP3]). These data, along with those for body composition (percent body fat vs lean mass), are particularly important for African-American survivors given the historically low levels of weight loss observed in interventions. Gathering body composition and biological data will enhance our understanding of how weight loss, even if minor amounts, may impact breast cancer recurrence risk and overall health risk among AfricanAmerican women.

\section{Methods/Design \\ Study design}

Moving Forward is a randomized trial that examines the effects of a culturally tailored guided weight loss program as compared to a self-guided weight loss program on the BMI, body composition and waist:hip circumference of 240 overweight/obese African-American breast cancer survivors. Diet and physical activity patterns, intermediate markers of breast cancer recurrence (i.e., sex hormones, markers of chronic inflammation and hyperinsulinemia), fatigue and quality of life will also be examined.

The study is based in eight Chicago Park District facilities located within communities that are predominantly African-American. Figure 1 provides an overview of the study design. Figure 2 provides an overview of the conceptual framework for the study.

\section{Ethics}

The study procedures were reviewed and approved for ethical treatment of human subjects by the University of Illinois at Chicago Institutional Review/Ethics Board.

\section{Procedures}

Women who respond to recruitment efforts complete a brief telephone interview to verify eligibility. Next, confirmation of stage I, II, or III breast cancer and approval for participation in a weight loss program that includes moderate physical activity is sought from the participant's primary care physician (PCP) and/or oncologist. Once eligibility is established, participants are asked to come in for an interview and physical assessment. At the beginning of this appointment, staff meets individually with each participant to obtain written informed consent. They then complete a 75-min in person interview, a blood draw, blood pressure measurement, dual energy $\mathrm{x}$-ray (DXA), and height and weight measurements. All 


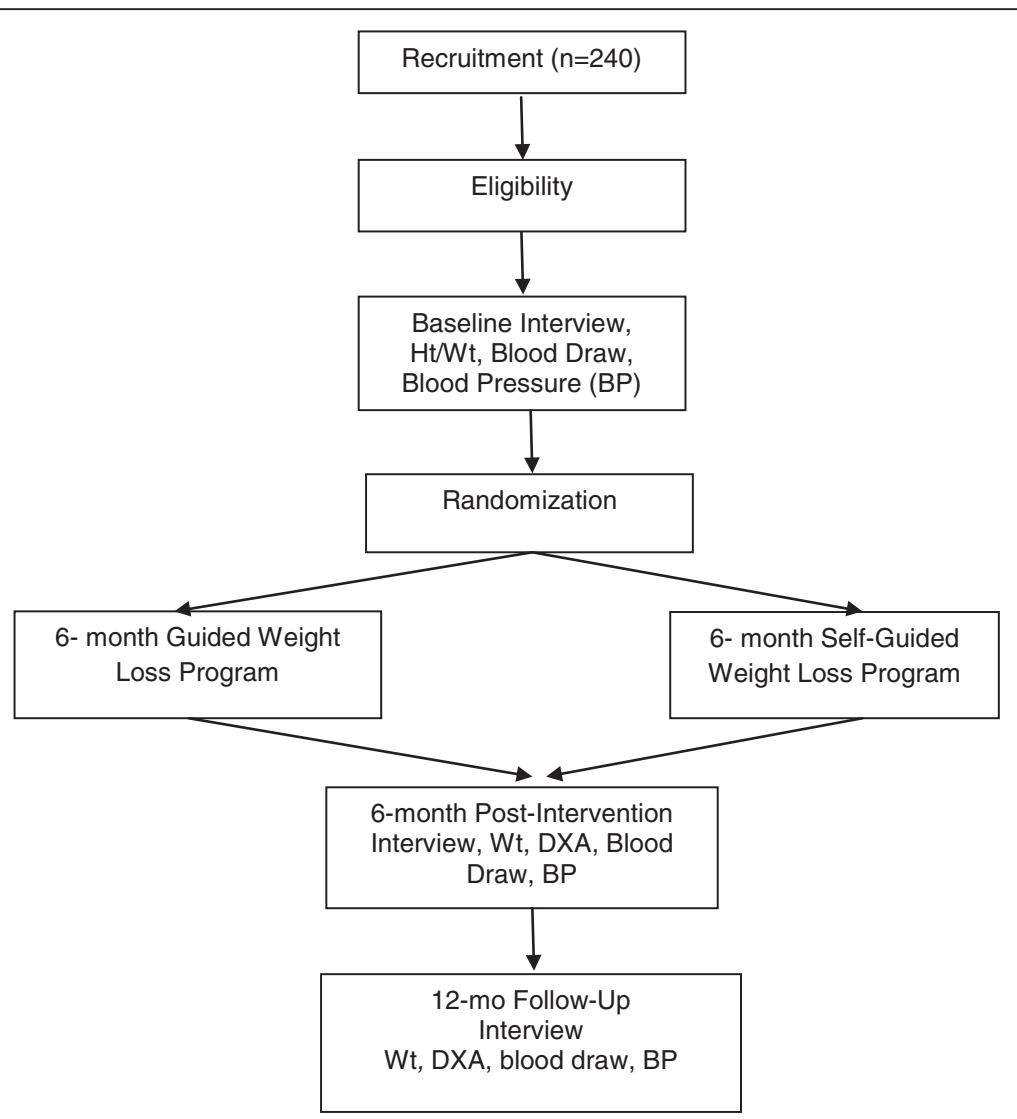

Fig. 1 Study Design

participants are also asked to wear an accelerometer for 7 days during waking hours. Participants receive a $\$ 20$ incentive for the interview, $\$ 10$ for the blood draw, $\$ 10$ for the DXA and $\$ 10$ for wearing the accelerometer. Subsequently, participants are randomly assigned to one of two 6-month interventions: (1) Moving Forward guided weight loss intervention (MFG) or (2) Moving Forward self-guided weight loss intervention (SG). Participants once again complete the entire assessment process post-intervention and at a 12-month follow-up.

\section{Recruitment}

Recruitment efforts include a number of different strategies. The most effective strategy relies on patient lists from cancer registries of three academic hospitals. Patients who were diagnosed with stages I, II, or III at least 6 months prior receive letters describing the study, followed by phone calls to assess interest and screen for eligibility. In addition, community-based efforts revolve around a number of community and institutional partners, including breast cancer support organizations, local

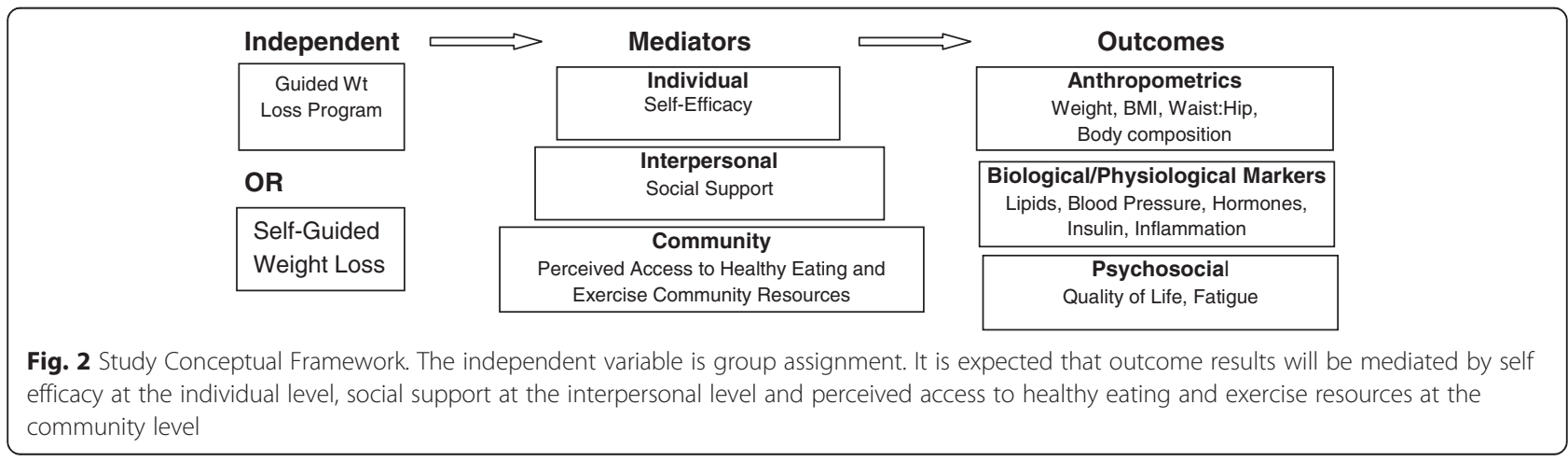


churches, block clubs, community centers and community leaders. We also post notices within on-line communities that serve the African-American community.

\section{Eligibility}

Inclusion criteria: (1) self-identify as Black or AfricanAmerican (including individuals who are bi-racial but identify themselves as Black or African-American); (2) female; (3) Stage I, II, or III invasive breast carcinoma; (4) completed treatment (surgery, chemotherapy and/or radiation) at least six months prior to recruitment (ongoing treatment with adjuvant endocrine therapies is acceptable); (5) age 18 or above at time of diagnosis; (6) Body Mass Index (BMI) at least $25 \mathrm{~kg} / \mathrm{m}^{2}$ - chosen because this includes only those participants who are overweight and would not be harmed by a $7 \%$ weight loss; (7) physically able to participate in a moderate physical activity program as assessed by self-report and PCP/oncologist approval; (8) agree to random assignment and data collection; and (9) able to attend twice weekly classes for six months.

Exclusion criteria: (1) plans to move from the community during the study; (2) currently pregnant, less than 3 months post-partum, or pregnancy anticipated during the study; (3) taking weight loss medication prescribed by a doctor; (4) participation in another structured weight loss program that uses special foods; or (5) weight loss surgery in the past year, or planned weight loss surgery in the next year.

\section{Measures}

\section{Demographics}

Demographic data include name, address, date of birth, marital status, number of children, education, occupational status, annual income, and insurance status.

\section{Breast cancer treatment history}

Diagnosis and treatment history (e.g., chemotherapy, radiation, previous and current adjuvant endocrine therapies) are collected from the treating oncologist and will be used for descriptive purposes only.

\section{Co-morbid conditions}

Respondents review a list of sixteen health problems (i.e., hypertension/high blood pressure, diabetes, arthritis) and report if they have ever been told by a doctor that they have this particular condition.

\section{Mediating variables}

\section{Social support for eating and exercise}

This questionnaire asks respondents to rate on a five point scale $(1=$ never, $5=$ very often $)$ how often friends and family have done or said certain things related to the respondents' efforts to change their dietary or exercise habits. Social support for eating habits is measured using two five-item subscales (encouragement and discouragement), each calculated separately for friends and family. Internal consistency coefficients range from 0.73 to 0.87 . Social support for exercise is measured using one 10-item scale, also calculated separately for family and friends [41].

\section{Self-efficacy for eating and exercise behaviors}

The Physical Activity and Nutrition Self-Efficacy scale is an 11-item instrument that assesses the participant's level of confidence that she can complete particular activities that promote weight loss [42]. This scale has adequate reliability, internal consistency, and construct validity, as well as good predictive validity among African-Americans.

\section{Perceived access to healthy eating and exercise}

These items come from the Robert Woods Johnson Active Where study [43]. Respondents rate their level of agreement (from $1=$ strongly agree to $4=$ strongly disagree) to four statements related to access to physical activity resources, five statements related to healthy eating resources, and five statements about perceived neighborhood safety. All scales show good internal consistency, with Cronbach's alphas from 0.78 to $0.94[43]$.

\section{Outcomes}

\section{Weight outcomes}

Body Mass Index (BMI) Height (baseline only) is measured to the nearest $0.1 \mathrm{~cm}$ using a portable stadiometer (Seca). Weight is measured to the nearest $0.1 \mathrm{~kg}$ using a digital scale (Tanita), with participants wearing light clothes without shoes. Two measurements for height and weight are taken. If there is a discrepancy of more than $0.5 \mathrm{~cm}$ for height or $0.2 \mathrm{~kg}$ for weight between the first and second measurements, a third measurement is taken. The mean of the two most closely aligned measurements is used to calculate BMI (weight $(\mathrm{kg}) /$ height $(\mathrm{m})^{2}$.

Waist to hip ratio Is measured with participants standing without outer garments and with empty pockets. Waist is measured to the nearest $0.1 \mathrm{~cm}$ at the level midway between the lower rib margin and the iliac crest, with the participant breathing out gently. Hip is recorded as the maximum circumference over the buttocks. Two measurements are taken. If there is a discrepancy of more than $1 \mathrm{~cm}$, a third measurement is taken. The mean of the two measurements most closely aligned is used for analyses. 
Body composition: Dual Energy X-ray Absorptiometry (DXA) DXA allows quantification of the amount of adipose tissue located within the abdominal area and also throughout the entire body of each participant. DXA provides precise, non-invasive measures of fat mass and lean tissue mass (total body, as well as regional) [44]. This method is rapid, requires minimal effort from study participants and compares favorably with hydrostatic weighing for measurement of body fat percentages [45]. DXA measurements of participants' total and regional fat and lean mass is conducted using the DXA Hologic $4500 \mathrm{~W}$ elite.

\section{Behavioral outcomes}

Diet Our goal is to determine group means for consumption of energy, fruits and vegetables, fat, and fiber. A semi-quantitative Food Frequency Questionnaire (FFQ) is the most appropriate tool in this case [46-48]. The Block 2005 FFQ [49] estimates the usual intake of a wide array of nutrients and food groups, and allows for calculation of the Healthy Eating Index (HEI). Reliability and validity are established for the measure in a wide range of age, gender, income, and ethnic groups $[50,51]$.

\section{Physical activity (self-report and objective)}

Modified activity questionnaire Kriska and Caspersen [52] The Modified Activity Questionnaire assesses selfreported leisure activity and television viewing. For leisure activity, respondents review a list of 17 popular activities (e.g., walking, gardening) and select those that they performed on at least 10 occasions in the last year. Participants are also given an opportunity to report leisure activities that are not on the list. Respondents then provide information on average frequency and duration for each activity. Responses are used to calculate the number of hours/week the participant engages in moderate and vigorous activity, along with total MET-hours per week. The questionnaire also asks how many hours per day the participant usually spends watching television. This activity questionnaire has been used in many large studies with diverse samples, including cancer survivors [53], and has well-established reliability and validity [52].

Godin leisure-time exercise questionnaire This brief questionnaire asks how many times in a typical 7-day period the participant performs strenuous, moderate, or mild exercise for more than 15 min during her free time. These responses are used to calculate a leisure activity score and to classify the respondent as active, moderately active, or insufficiently active [54].

Accelerometer The limitations of self-reported physical activity are well established [55]. Therefore, the ActiGraph
GT3X activity monitor is used to obtain an objective measure of physical activity. The ActiGraph is a small, lightweight accelerometer designed to detect normal body motion. Participants are asked to wear the ActiGraph during waking hours for seven days. Only days on which the participant wore the accelerometers at least $10 \mathrm{~h}$ are included, and participants with fewer than four valid days are excluded from analyses. Thresholds suggested by Troiano and colleagues will be used to calculate the amount of time spent in moderate and vigorous physical activity $[56,57]$.

\section{Biological/physiological outcomes}

Biomarkers of breast cancer recurrence risk A fasting blood sample is drawn according to standard procedures by a clinical research center phlebotomist. We chose markers for three proposed mechanisms by which obesity may contribute to breast cancer progression: altering levels of sex hormones (markers: estradiol, estrogen, sex hormone-binding globulin, testosterone), hyperinsulinemia (markers: IGF-I, IGBP3, C-peptide), and chronic inflammation (marker: C-reactive protein, IL-6) [58]. Staff at the clinical research center processes the blood samples according to standard procedures for storage. Briefly, a total of $30 \mathrm{ml}$ of blood is collected in red top vacutainer tubes (without anticoagulant). Blood (approximately $15 \mathrm{ml}$ ) is allowed to clot for $20 \mathrm{~min}$ and subsequently centrifuged at $2500 \mathrm{rpm}$ for $20 \mathrm{~min}$ to separate serum. Staff collects, aliquots serum, which is frozen at $-80{ }^{\circ} \mathrm{C}$ until analysis. All breast cancer biomarkers are measured using commercially available ELISA kits (R\&D Systems and Alpco). Each sample is assayed in duplicate and repeated if variability exceeds $15 \%$. We will monitor quality control of laboratory tests by ensuring internal positive and negative controls are within the parameters of the test kit for each assay and by evaluating for trends over time.

Biomarkers of Co-morbidities Some of the collected blood is used to examine lipid profiles (HDL, LDL, triglycerides) as a marker of dyslipidemia and Hemoglobin A1c as a marker of impaired glucose tolerance. Individuals with an A1c level at or above $6.5 \%$ who do not report a history of diabetes are informed of the result, provided counseling, and encouraged to follow up with their primary care providers. Hypertension is assessed by measuring diastolic and systolic blood pressure with an OMRON IntelliSense blood pressure monitor using a standard protocol.

\section{Psychosocial outcomes}

Quality of life The patient-reported outcomes measurement information system (PROMIS) Global Health measure [59] consists of 10 self-reported global health 
items selected as an efficient way to gather general perceptions of health. The PROMIS items assess 5 domains: physical function, pain, fatigue, emotional distress, and social health. Two dimensions representing physical and mental health underlie the global health items in PROMIS. These global health scales can be used to efficiently summarize physical and mental health in patient-oriented studies.

Fatigue The Brief Fatigue Inventory is a reliable nineitem instrument that uses $0-10$ numeric rating scales to evaluate severity of fatigue. A global fatigue score is calculated by taking the mean of the 9 items [60].

Symptom checklist The Breast Cancer Symptom Checklist (BCSCL) was originally developed for the Breast Cancer Prevention Trial and has been validated with a variety of breast cancer populations, including survivors [61]. Respondents are asked if they have experienced any of 17 listed symptoms and then rate the severity on a 5-point Likert-type scale from 0 (not at all bothered) to 4 (extremely bothered). This measure provides scale scores for eight clusters of symptoms: cognitive/mood symptoms, musculoskeletal pain, vasomotor symptoms, nausea, sexual problems, bladder problems, arm problems and body image. We modified the measure and did not include the nausea and sexual problems scales based on advisory board feedback.

\section{Intervention}

Participants are randomized to either the Moving Forward Guided program (MFG) or the Moving Forward Self-Guided program (SG) for six months. MFG includes in-person classes and text messaging, while the SG includes a curriculum manual with handouts related to the intervention topics, but no classes or text messaging.

\section{Moving forward}

The intervention was developed based on formative qualitative work with African-American breast cancer survivors, followed by a pilot of the guided program that led to further refinements [30,62].

\section{Theoretical framework}

The Moving Forward intervention integrates concepts from Social Cognitive Theory (SCT) [63] and the SocioEcological Model (SEM) [64, 65] to promote behavior change. SCT suggests that behavior can be explained by the dynamic interaction between behavior, personal factors (e.g., self-efficacy), and the environment (e.g., social support [66-70]. The intervention also incorporates tenets of the socio-ecological model (SEM) [64, 65], a model that goes beyond individual-level variables and emphasizes that support from the larger social context is needed for long-term behavior change [71]. Accordingly, SEM posits that weight status, diet, and physical activity are influenced by individual (e.g., beliefs, taste preferences), interpersonal (e.g., social support, traditions and role expectations), and community factors (e.g., access to resources that support health promotion) [72]. Interventions hoping to promote long-term behavior change must address these three levels of influence [73, 74]. Moving Forward accomplishes this by addressing: (1) Individual factors - acknowledging heavier body image ideals, identifying and addressing personal barriers to behavior change; (2) Interpersonal - the importance of food in the African-American culture and finding ways to integrate this value with healthful eating; providing low-fat versions of culturally traditional "soul food" recipes; acknowledging and addressing family roles and family resistance/support to change; providing information on integrating healthful lifestyle practices for the family; facilitating social support for making changes in diet, physical activity, and weight; understanding the important role of religion and worship in the women's lives and how it affects their health perspectives and (3) Community - incorporating a sustainable link to a community physical activity resource that can address barriers to regular physical activity (i.e., safety, weather, access); problem solving around cost and availability of healthy food; introducing participants to unfamiliar community resources. Interestingly, a positive sense of community (e.g., social bonds between individuals and between individuals and their community) is associated with selfefficacy for physical activity among African-American women [75].

\section{Intervention goals}

The overall goal of Moving Forward is to make changes in health behaviors to promote a healthy weight. The weight loss goal is $7 \%$ of baseline body weight (1-2 lbs. per week), consistent with the recommendations of an expert panel at National Institutes of Health [76]. Dietary goals aimed at producing weight loss, decreasing breast cancer recurrence risk, and improving overall health include: (1) a decrease in daily caloric intake (based on weight in pounds X 12 caloriesl/day, with 500-750 cal subtracted to create an energy deficit); (2) a decrease in dietary fat consumption to $20 \%$ of total calories; (3) an increase in fruit and vegetable consumption to 7 daily servings; and (4) an increase in fiber to $25 \mathrm{~g}$ per day. For exercise, participants are advised to gradually increase their activity to a minimum of $180 \mathrm{~min}$ per week at $55-65 \%$ maximal heart rate.

\section{Moving Forward Guided Program Structure (MFG)}

The MFG program meets twice a week for 26 weeks (see Table 1 for weekly themes) and is led by a team that 
Table 1 Moving forward weight loss program weekly topics

\begin{tabular}{|c|c|}
\hline Week 1 & Introduction to program \\
\hline Week 2 & Self-monitoring and goal setting \\
\hline Week 3 & $\begin{array}{l}\text { Using self-monitoring tools to make } \\
\text { better choices }\end{array}$ \\
\hline Week 4 & Energy requirements \\
\hline Week 5 & Reading food labels and monitoring heart rate \\
\hline Week 6 & Measuring portions \\
\hline Week 7 & $\begin{array}{l}\text { Breakfast and water }-2 \text { key tools to } \\
\text { losing weight }\end{array}$ \\
\hline Week 8 & Healthy grocery shopping \\
\hline Week 9 & Meal planning \\
\hline Week 10 & $\begin{array}{l}\text { Holiday eating (scheduled } \\
\text { according to when holiday falls) }\end{array}$ \\
\hline Week 11 & Stimulus control \\
\hline Week 12 & Mindful eating \\
\hline Week 13 & $\begin{array}{l}\text { Eating away from home - restaurant } \\
\text { and party strategies }\end{array}$ \\
\hline Week 14 & $\begin{array}{l}\text { Program review - where were you, } \\
\text { where are you now? }\end{array}$ \\
\hline Week 15 & Building movement into your daily life \\
\hline Week 16 & Barriers to healthy eating and exercise \\
\hline Week 17 & Problem solving \\
\hline Week 18 & The power of habit \\
\hline Week 19 & Strategies to increase fruits and vegetables \\
\hline Week 20 & $\begin{array}{l}\text { Where you were, where you are } \\
\text { and where you plan to go }\end{array}$ \\
\hline Week 21 & $\begin{array}{l}\text { Relapse preventioin I - what is a } \\
\text { lapse vs relapse }\end{array}$ \\
\hline Week 22 & $\begin{array}{l}\text { Relapse prevention II - identifying } \\
\text { high risk situations }\end{array}$ \\
\hline Week 23 & $\begin{array}{l}\text { Relapse prevention III - maintaining } \\
\text { a physically active lifestyle }\end{array}$ \\
\hline Week 24 & $\begin{array}{l}\text { Relapse prevention IV - motivation } \\
\text { to maintain changes }\end{array}$ \\
\hline Week 25 & $\begin{array}{l}\text { Transitioning from Moving Forward to } \\
\text { being on your own }\end{array}$ \\
\hline Week 26 & Graduation \\
\hline
\end{tabular}

includes a community dietitian, a community cancer exercise instructor, and a health psychologist. The program is conducted in city park district facilities, where participants enjoy free memberships, ongoing access to classes and fitness rooms, and the opportunity to maintain contact with program participants once the program concludes. The first meeting each week includes a 60-min class that addresses knowledge (e.g., relationship between obesity and breast cancer; food label reading; portions; available healthy living community resources), attitudes (e.g., pros and cons of weight loss; understanding the roles that food plays in one's life; the concept of "fail to plan, plan to fail") and cognitive behavioral strategies including self-monitoring of weight, food and physical activity; realistic goal setting; stimulus control; problem solving; mindfulness; cognitive restructuring and relapse prevention. These classes are led by a dietitian, a psychologist and a certified cancer exercise trainer. Table 1 provides a list of weekly curriculum topics. Pilot data showed that many women entered the program with low levels of knowledge about healthy eating and exercise. Thus, the first weeks are devoted to teaching core concepts (e.g., concept of calories in/out, food label reading, measuring heart rate), while later weeks are focused on cognitive-behavioral aspects of weight loss such as stimulus control, habit and mindfulness. Class activities include weighing in weekly; completing a food and activity self-monitoring record; increasing awareness of portions by weighing and measuring foods according to one's typical portions and then according to recommended portions; creating stimulus control plans for home, car and work; identifying barriers to healthy eating and/or exercise and problem solving within small groups; going on a field trip to a local grocery store to practice reading food labels; creating an eating-out management plan; and identifying high-risk situations and brainstorming ways to manage them. The first weekly meeting also includes a support "icebreaker" (share the funniest moment of your breast cancer journey; what has been the most frustrating; etc.) and a 60min exercise class taught by a certified cancer exercise trainer.

The second weekly meeting is a 60 -min exercise class taught by a cancer exercise trainer. The exercise classes incorporate a variety of activities, including traditional aerobics, line dancing, African dance, salsa, yoga, Pilates, and strength and flexibility training. Class time is also spent learning to use the park district fitness facility equipment to ensure that women feel comfortable and competent on the equipment, thus promoting enhanced self-efficacy and mastery of new skills. Many participants enter the program at very low levels of fitness; therefore, physical activity levels are increased gradually with special attention to concerns such as lymphedema and balance. Increased physical activity outside of class is encouraged by suggesting enrollment in additional local exercise classes, providing safe outdoor walking routes, and alerting women to activity resources online and on FitTV.

Participants often need further support and reinforcement of lifestyle changes outside of class, as well as timely information related to healthy eating and exercise resources. To provide this efficiently and effectively, MFG uses text messaging, a strategy successfully used in previous weight loss interventions with low income African-American women [77, 78]. A custom software application, mytapp, allows the psychologist and 
trainers to schedule two text messages each week to be sent to participants. Messages are less than 200 characters in length and are written to be brief, clear and motivational. The intent is to reinforce concepts covered in class while also supporting self-efficacy, social support and perceived access. For example, during the week that the intervention covers portions, participants receive a text that reads, "Are you using your measuring cups and spoons?" In the week that we cover mindfulness, the message states, "Breathe, Breathe deeply. You CAN savor each bite." At the end of the six-month program, MFG participants receive six monthly newsletters to review and support concepts related to integrating and maintaining healthy lifestyle habits. They also receive supportive weekly text messages until the final data collection.

\section{Moving Forward Self-Guided Program (SG)}

Participants randomized to the SG receive a program binder that is divided into 26 sections, with each section addressing the topics listed in Table 1 . Within each section is a brief guide to the topic and accompanying worksheets, handouts or activities to complete. Administrative study staff (not intervention staff) meet briefly (approximately $15 \mathrm{~min}$ ) with the SG participants once individually to give them their binder and to provide an orientation to its layout and contents. Staff follows up with a monthly check-in phone call. At the end of the six months, SG participants also receive the monthly newsletters for six months until the final follow-up data collection.

\section{Randomization}

Approximately one week before the intervention begins at each site, women who completed the baseline visit are randomized in a single block. The allocation assignments for each site are generated using a SAS program written by the data analyst, who has no contact with participants.

A few participants may be unable to complete the baseline visit before the main randomization round. In these cases, the data analyst prepares sealed, numbered envelopes containing the next allocation assignments for the site. As each woman completes her baseline visit, she is assigned the next envelope in the series.

\section{Statistical analyses}

\section{Power computations}

Calculations were conducted for hierarchical longitudinal designs with differential attrition rates using software provided by Roy et al. [79] Results showed that an initial sample of 240 participants is sufficient to detect an effect size of 0.4 , assuming attrition of about $10 \%$ at each time point with power of 0.8 for a two -tailed test.
Power will increase with the inter-correlation of observations over time, which we estimated conservatively at 0.4 . The addition of covariates to the model will also increase power.

\section{Data analysis}

For a two-group randomized trial with repeated measures the mixed (multilevel) model is the preferred mode of data analysis [80]. With only two time points, the analysis reduces to a test of the difference between treatment groups in gains or losses in the outcome variable between baseline and 6-month follow up. The model easily generalizes to three time points (including the 12month visit), in which case time can be indexed in simple linear fashion or represented either in quadratic form or via indicator variables for the first and second follow up measures. In that case, the analysis focuses on between group differences in outcome trajectories over time.

Our hypothesis is that subjects in the MFG condition will experience greater rates of weight loss, improved diet and physical activity patterns and other positive outcomes than subjects in the SG group. A major advantage of casting data analysis in the framework of the generalized linear (regression) model is that it easily accommodates covariates. One important covariate is time since diagnosis, which will be included in all analyses. A potentially important aspect of our modeling will be the investigation of dose-response effects. We will have data on frequency and pattern of attendance for each subject, which will allow us to model outcomes as a function of intensity of treatment.

\section{Discussion}

This novel study examines the efficacy of a communitybased weight loss program for African-American breast cancer survivors. Few behavioral interventions have targeted this high-risk population. Observational data highlight unhealthy eating and sedentary physical activity patterns among African-American breast cancer survivors, while qualitative data document their interest in making lifestyle changes to lose weight $[62,81]$. Unfortunately, many survivors (regardless of race) are confused by the various dietary and physical activity recommendations, struggle with effective weight loss strategies, and relate a need for more structured programming [62]. Urban African-American women face further barriers in their quest to practice healthy lifestyles. Many AfricanAmericans in the general population live in economically stressed neighborhoods where access to fresh fruits and vegetables may be limited or cost prohibitive, but cheaper high-fat foods are easily accessible $[82,83]$. In addition, opportunities for physical activity in disadvantaged communities are often limited by a lack of safe 
open spaces, sidewalks in disrepair, gang violence, poor lighting, and insufficient police [84]. Focus groups with African-American breast cancer survivors highlight other important barriers, as well as facilitators. Barriers include pain, family commitments and lack of social support; facilitators include faith and spirituality, family and friend support, and desire to reduce overall health risks and risk of recurrence $[62,81]$. If lifestyle change interventions are to be successful, barriers and facilitators must be addressed.

The Moving Forward intervention trial was developed in response to the recognized need for comprehensive weight loss programs that integrate cognitive-behavioral strategies related to lifestyle changes and the unique psychosocial needs of African-American breast cancer survivors. Recruitment and retention can be challenging for research targeting minority communities. To address this, the study team participates in a number of activities, such as health fairs, breast cancer survivor groups, health ministries, radio programs and educational forums within the African-American community. An important goal is to provide meaningful connections and information that meet the needs of this chronically underserved community. It is understood that regardless of whether women join the study, we are taking steps to build knowledge and trust to facilitate participation in health promoting activities and even future research studies that may benefit the women, their friends or families. Once women are involved in the study, we are particularly mindful of maintaining ongoing communication, as well as relating the value of their research participation. In addition, we prioritized conducting the program within the community to promote sustainability and to facilitate study retention by helping women from the same neighborhood connect with other breast cancer survivors.

Study data will contribute to a better understanding of the impact of weight loss on behavioral, psychosocial and biological outcomes among African-American breast cancer survivors. Unique to this study is its measurement of body composition and biological markers for both overall health and breast cancer recurrence risk. Previous weight loss interventions with African-American women, in general, report relatively small amounts of weight loss [85]. It is not clear if these losses correspond to equally small changes in body composition and biological markers of overall health and breast cancer recurrence. Results will improve our understanding of how behavior change and weight loss affect pathways associated with breast cancer recurrence and chronic disease risk, as well as those associated with quality of life and symptoms. If the intervention is successful, identifying optimal channels for dissemination will be critical.

\section{Abbreviations}

CRP: C-reactive protein; IL-6: Interleukin-6; TNF-a: Tumor necrosis factor; IGF1: Insulin-like growth factor-l; IGF-BP3: Insulin-like growth factor-binding protein-3; DXA: Dual energy x-ray; MFG: Moving Forward guided weight loss intervention; SG: Moving Forward self-guided weight loss intervention; BMI: Body Mass Index; FFQ: Food frequency questionnaire; PROMIS: Patientreported outcomes measurement information system; SCT: Social Cognitive Theory; SEM: Socio-Ecological Model.

\section{Competing interests}

Dr. Stolley received funding from the National Cancer Institute to conduct the study. Aside from this funding, the authors declare that they have no competing interests.

\section{Authors' contributions}

MS conceived of study design, developed and is conducting the intervention, and oversees all aspects of study conduct. She wrote the original manuscript with substantive contribution and feedback from co-authors.

LKS contributed greatly to study conception and design. She was involved in substantive reviews and revisions of the manuscript. She read and provided final approval.

GF contributed to the development of procedures and analysis of biomarker data. She reviewed the manuscript and provided final approval. CA played a signficant role in writing the methods section. She read and provided final approval for the manuscript.

PS contributed to background, methods and discussion related to body composition measurement. She reviewed manuscript, provided revisions and provided final approval for manuscript.

LS contributed significantly to the writing and revising of methods and the analysis section. She read and provided final approval for manuscript. $\mathrm{RC}$ wrote the analysis section and reviewed/revised all other sections. He provided final approval of manuscript.

BG contributed to the development and write-up of the intervention, developed the mytapp text messaging platform, reviewed/revised the manuscript and gave his final approval for submission. All authors have read and approved the manuscript.

\section{Acknowledgements}

Grant sponsor: National Cancer Institute, Grant Number R01CA15440.

\section{Author details}

${ }^{1}$ Cancer Center and Department of Medicine, Medical College of Wisconsin, 8701 Watertown Plank Road, Milwaukee, WI 53226-3548, USA. ${ }^{2}$ Institute for Health Research and Policy, University of Illinois at Chicago (UIC), Chicago, IL, USA. ${ }^{3}$ Department of Pharmacy Systems, Outcome \& Policy, UIC, College of Pharmacy, Chicago, IL, USA. ${ }^{4}$ Department of Kinesiology and Nutrition, UIC, College of Applied Health Sciences, Chicago, IL, USA. ${ }^{5}$ School of Nursing,

Loyola University, Maywood, IL 60153, USA.

Received: 26 March 2015 Accepted: 14 December 2015

Published online: 29 December 2015

References

1. American Cancer Society. Cancer Facts and Figures 2004. Atlanta, GA: American Cancer Society; 2004

2. Joslyn SA, West MM. Racial differences in breast carcinoma survival. Cancer. 2000;88(1):114-23.

3. Newman LA, Griffith KA, Jatoi I, Simon MS, Crowe JP, Colditz GA. MetaAnalysis of Survival in African American and White American Patients With Breast Cancer: Ethnicity Compared With Socioeconomic Status. J Clin Oncol. 2006;24(9):1342-9.

4. National Cancer Institute. In: Altekruse S, Kosary C, Krapcho M, Neyman N, Aminou R, Waldron W, Ruhl J, Howlader N, Tatalovich Z, Cho H, et al., editors. SEER Cancer Statistics Review, 1975-2007. Bethesda, MD: National Cancer Institute; 2010.

5. Tammemagi CM, Nerenz D, Neslund-Dudas C, Feldkamp C, Nathanson D. Comorbidity and Survival Disparities Among Black and White Patients With Breast Cancer. JAMA. 2005;294(14):1765-72.

6. Eley JW, Hill HA, Chen WW, Austin DF, Wesley MN, Muss HB. Racial differences in survival from breast cancer. Results of the National Cancer Institute Black/ White Cancer Survival Study. JAMA. 1994;272(12):947-54. 
7. Gerend MA, Pai M. Social determinants of Black-White disparities in breast cancer mortality: a review. Cancer Epidemiol Biomarkers Prev. 2008;17(11): 2913-23.

8. Chlebowski RT, Aiello E, McTiernan A. Weight loss in breast cancer patient management. J Clin Oncol. 2002;20(4):1128-43.

9. Dignam JJ, Wieand K, Johnson KA, Fisher B, Xu L, Mamounas EP. Obesity, Tamoxifen Use, and Outcomes in Women With Estrogen Receptor-Positive Early-Stage Breast Cancer. J Natl Cancer Inst. 2003;95(19):1467-76.

10. Stephenson GD, Rose DP. Breast cancer and obesity: an update. Nutrition Cancer. 2003:45(1):1-16.

11. McCullough ML, Feigelson HS, Diver WR, Patel AV, Thun MJ, Calle EE. Risk Factors for Fatal Breast Cancer in African-American Women and White Women in a Large US Prospective Cohort. Am J Epidemiol. 2005;162(8):734-42.

12. McKenzie F, Jeffreys M. Do Lifestyle or Social Factors Explain Ethnic/Racial Inequalities in Breast Cancer Survival? Epidemiol Rev. 2009;31:52-66.

13. Nichols HB, Trentham-Dietz A, Egan KM, Titus-Ernstoff L, Holmes MD, Bersch AJ, et al. Body Mass Index Before and After Breast Cancer Diagnosis: Associations with All-Cause, Breast Cancer, and Cardiovascular Disease Mortality. Cancer Epidemiol Biomark Prev. 2009;18(5):1403-9.

14. Reeves GK, Patterson J, Vessey MP, Yeates D, Jones L. Hormonal and other factors in relation to survival among breast cancer patients. Int J Cancer. 2000;89(3):293-9.

15. Vatten LJ, Foss OP, Kvinnsland S. Overall survival of breast cancer patients in relation to preclinically determined total serum cholesterol, body mass index, height and cigarette smoking: a population-based study. Eur J Cancer. 1991;27(5):641-6.

16. Kyogoku S, Hirohata T, Takeshita S, Nomura Y, Shigematsu T, Horie A. Survival of breast-cancer patients and body size indicators. Int J Cancer. 1990:46(5):824-31.

17. Endogenous Hormones Breast Cancer Collaborative G. Body Mass Index, Serum Sex Hormones, and Breast Cancer Risk in Postmenopausal Women. J Natl Cancer Inst. 2003;95(16):1218-26.

18. McTiernan A, Rajan KB, Tworoger SS, Irwin M, Bernstein L, Baumgartner $R$, et al. Adiposity and Sex Hormones in Postmenopausal Breast Cancer Survivors. J Clin Oncol. 2003:21(10):1961-6.

19. Goodwin PJ, Ennis M, Pritchard Kl, Trudeau ME, Koo J, Madarnas Y, et al. Fasting Insulin and Outcome in Early-Stage Breast Cancer: Results of a Prospective Cohort Study. J Clin Oncol. 2002;20(1):42-51.

20. Blackburn GL, Wang KA. Dietary fat reduction and breast cancer outcome: results from the Women's Intervention Nutrition Study (WINS). Am J Clin Nutr. 2007;86(3):878S-81S.

21. Pierce BL, Ballard-Barbash R, Bernstein L, Baumgartner RN, Neuhouser ML, Wener $\mathrm{MH}$, et al. Elevated Biomarkers of Inflammation Are Associated With Reduced Survival Among Breast Cancer Patients. J Clin Oncol. 2009:27(21):3437-44.

22. Ogden $\mathrm{CL}$, Carroll MD, Kit BK, Flegal KM. Prevalence of childhood and adult obesity in the United States, 2011-2012. JAMA. 2014;311(8):806-14.

23. Kant AK, Graubard BI, Kumanyika SK. Trends in Black-White Differentials in Dietary Intakes of U.S. Adults, 1971-2002. Am J Prev Med. 2007;32(4):264-72.

24. Must A, Spadano J, Coakley EH, Field AE, Colditz G, Dietz WH. The disease burden associated with overweight and obesity. JAMA. 1999;282(16):1523-9.

25. Whitt M, Kumanyika S, Bellamy S. Amount and Bouts of Physical Activity in a Sample of African-American Women. Med Sci Sports Exerc 2003;35(11):1887-93.

26. Dennis Parker EA, Sheppard VB, Adams-Campbell L. Compliance with national nutrition recommendations among breast cancer survivors in "Stepping Stone". Integr Cancer Ther. 2014;13(2):114-20.

27. Paxton RJ, Jones LA, Chang S, Hernandez M, Hajek RA, Flatt SW, et al. Was race a factor in the outcomes of the women's health eating and living study? Cancer. 2011;117(16):3805-13.

28. Paxton RJ, Taylor WC, Chang S, Courneya KS, Jones LA. Lifestyle behaviors of African American breast cancer survivors: a Sisters Network, Inc. study. PLoS One. 2013;8(4):e61854

29. Chlebowski RT, Chen Z, Anderson GL, Rohan T, Aragaki A, Lane D, et al. Ethnicity and Breast Cancer: Factors Influencing Differences in Incidence and Outcome. J Natl Cancer Inst. 2005;97(6):439-48.

30. Stolley MR, Sharp LK, Oh A, Schiffer L. A weight loss intervention for African American breast cancer survivors, 2006. Prev Chronic Dis. 2009;6(1):A22.

31. Djuric Z, Mirasolo J, Kimbrough LV, Brown DR, Heilbrun LK, Canar L, et al. A Pilot Trial of Spirituality Counseling for Weight Loss Maintenance in African American Breast Cancer Survivors. J Natl Med Assoc. 2009;101(6):552.
32. Djuric Z, DiLaura NM, Jenkins I, Darga L, Jen CKL, Mood D, et al. Combining Weight-Loss Counseling with the Weight Watchers Plan for Obese Breast Cancer Survivors. Obes Res. 2002;10(7):657-65.

33. Mefferd K, Nichols J, Pakiz B, Rock C. A cognitive behavioral therapy intervention to promote weight loss improves body composition and blood lipid profiles among overweight breast cancer survivors. Breast Cancer Res Treat. 2007;104(2):145-52.

34. de Waard F, Ramlau R, Mulders $Y$, de Vries T, van Waveren S. A feasibility study on weight reduction in obese postmenopausal breast cancer patients. Eur J Cancer Prev. 1993;2(3):233-8.

35. Goodwin P, Esplen MJ, Butler K, Winocur J, Pritchard K, Brazel S, et al. Multidisciplinary weight management in locoregional breast cancer: results of a phase II study. Breast Cancer Res Treat. 1998:48(1):53-64.

36. McTiernan A, Ulrich C, Kumai C, Bean D, Schwartz RM, Mahloch J, et al. Anthropometric and hormone effects of an eight-week exercise-diet intervention in breast cancer patients: results of a pilot study. Cancer Epidemiol Biomark Prev. 1998;7(6):477-81.

37. Foster GD, Wadden TA, Swain RM, Anderson DA, Vogt RA. Changes in resting energy expenditure after weight loss in obese African American and white women. Am J Clin Nutr. 1999;69(1):13-7.

38. Kumanyika S. Obesity Treatment in Minorities. In: Wadden T, Stunkard A, editors Handbook of Obesity Treatment. New York: Guilford Press; 2002. p. 416-46.

39. Greenlee HA, Crew KD, Mata JM, McKinley PS, Rundle AG, Zhang W, et al. A pilot randomized controlled trial of a commercial diet and exercise weight loss program in minority breast cancer survivors. Obesity (Silver Spring). 2013;21(1):65-76.

40. Wilson DB, Porter JS, Parker G, Kilpatrick J. Anthropometric changes using a walking intervention in African American breast cancer survivors: a pilot study. Prev Chronic Dis. 2005;2(2):A16.

41. Sallis JF, Grossman RM, Pinski RB, Patterson TL, Nader PR. The development of scales to measure social support for diet and exercise behaviors. Prev Med. 1987;16(6):825-36.

42. Latimer L, Walker LO, Kim S, Pasch KE, Sterling BS. Self-efficacy scale for weight loss among multi-ethnic women of lower income: a psychometric evaluation. J Nutr Educ Behav. 2011;43(4):279-83.

43. Grow HM, Saelens BE, Kerr J, Durant NH, Norman GJ, Sallis JF. Where Are Youth Active? Roles of Proximity, Active Transport, and Built Environment. Med Sci Sports Exerc. 2008:40(12):2071-9.

44. Friedl KE, DeLuca JP, Marchitelli LJ, Vogel JA. Reliability of body-fat estimations from a four-compartment model by using density, body water, and bone mineral measurements. Am J Clin Nutr. 1992;55(4):764-70.

45. Going SB, Massett MP, Hall MC, Bare LA, Root PA, Williams DP, et al. Detection of small changes in body composition by dual-energy $\mathrm{x}$-ray absorptiometry. Am J Clin Nutr. 1993;57(6):845-50.

46. Beaton $\mathrm{GH}$. Approaches to analysis of dietary data: relationship between planned analyses and choice of methodology. Am J Clin Nutr. 1994;59: 253S-62S.

47. Block G, Hartman AM, Dresser CM, Carroll MD, Gannon J, Gardner L. A databased approach to diet questionnaire design and testing. Am J Epidemiol. 1986;124(3):453-69.

48. Liu K. Statistical issues related to semiquantitative food-frequency questionnaires. Am J Clin Nutr. 1994;59:262S-5S.

49. Block G, Hartman AM, Naughton D. A reduced dietary questionnaire: development and validation. Epidemiology. 1990;1(1):58-64.

50. Norris J, Harnack L, Carmichael S, Pouane T, Wakimoto P, Block G. U.S. trends in nutrient intake: the 1987 and 1992 National Health Interview Surveys. Am J Public Health. 1997:87(5):740-6.

51. Hartman AM, Block G, Chan W, Williams J, McAdams M, Banks Jr WL. Reproducibility of a self-administered diet history questionnaire administered three times over three different seasons. Nutr Cancer. 1996; 25(3):305-15.

52. Kriska AM, Caspersen CJ. Introduction to a Collection of Physical Activity Questionnaires. Med Sci Sports Exerc. 1997;29(6):5.

53. Irwin ML, Crumley D, McTiernan A, Bernstein L, Baumgartner R, Gilliland FD, et al. Physical activity levels before and after a diagnosis of breast carcinoma. Cancer. 2003:97(7):1746-57.

54. Godin G, Shephard R. Godin leisure-time exercise questionnaire. Med Sci Sports Exerc. 1997;29(6s):S36.

55. Ainsworth BE, Sternfeld B, Slattery ML, Daguise V, Zahm SH. Physical activity and breast cancer: evaluation of physical activity assessment methods. Cancer. 1998;83(3 Suppl):611-20. 
56. Troiano RP, Berrigan D, Dodd KW, Mâsse LC, Tilert T, McDowell M. Physical activity in the United States measured by accelerometer. Med Sci Sports Exerc. 2008:40(1):181-8.

57. Sasaki JE, John D, Freedson PS. Validation and comparison of ActiGraph activity monitors. J Sci Med Sport. 2011;14(5):411-6.

58. Carmichael AR. Obesity and prognosis of breast cancer. Obes Rev. 2006;7(4): 333-40.

59. Cella D, Yount S, Rothrock N, Gershon R, Cook K, Reeve B, et al. The PatientReported Outcomes Measurement Information System (PROMIS): progress of an NIH Roadmap cooperative group during its first two years. Med Care. 2007;45(5 Suppl 1):S3-S11.

60. Mendoza TR, Wang XS, Cleeland CS, Morrissey M, Johnson BA, Wendt JK, et al. The rapid assessment of fatigue severity in cancer patients: use of the Brief Fatigue Inventory. Cancer. 1999;85(5):1186-96.

61. Stanton AL, Bernaards CA, Ganz PA. The BCPT symptom scales: a measure of physical symptoms for women diagnosed with or at risk for breast cancer. J Natl Cancer Inst. 2005;97(6):448-56.

62. Stolley MR, Sharp LK, Wells AM, Simon N, Schiffer L. Health Behaviors and Breast Cancer: Experiences of Urban African American Women. Health Educ Behav. 2006:33(5):604-24

63. Bandura A. Social Foundations of Thought and Action. Englewood Cliffs, NJ: Prentice-Hall; 1986.

64. Stokols D. Translating social ecological theory into guidelines for community health promotion. Am J Health Promot. 1996;10(4):282-98.

65. Richard L, Potvin L, Kishchuk N, Prlic H. Assessment of the integration of the ecological approach in health promotion programs. Am J Health Promot. 1996;10(4):318-28.

66. Martin PD, Dutton GR, Brantley PJ. Self-Efficacy as a Predictor of Weight Change in African-American Women[ast][ast]. Obesity. 2004;12(4):646-51.

67. Walcott-Mcquigg J. Psychological factors influencing cardiovascular risk reduction behavior in low and middle income African-American women. Natl Black Nurses Assoc. 2000;11(1):27-35.

68. Ainsworth BE, Wilcox S, Thompson WW, Richter DL, Henderson KA. Personal, social, and physical environmental correlates of physical activity in AfricanAmerican women in South Carolina. Am J Prev Med. 2003;25(3, Supplement 1):23-9.

69. Thomas JL, Stewart DW, Lynam IM, Daley CM, Befort C, Scherber RM, et al. Support needs of overweight African American women for weight loss. (Report). Am J Health Behav. 2009;33(4):339. 314).

70. Wolfe W. A review: maximizing social support-a neglected strategy for improving weight management with African-American women. Ethn Dis. 2004;14(2):212-8.

71. King AC, Jeffery RW, Fridinger F, Dusenbury L, Provence S, Hedlund SA, et al. Environmental and Policy Approaches to Cardiovascular Disease Prevention Through Physical Activity: Issues and Opportunities. Health Educ Behav. 1995;22(4):499-511.

72. Robinson T. Applying the Socio-ecological Model to Improving Fruit and Vegetable Intake Among Low-Income African Americans. J Community Health. 2008;33(6):395-406.

73. Kumanyika S. Ethnic minorities and weight control research priorities: Where are we now and where do we need to be? Prev Med. 2008;47(6):583-6.

74. Huang TT, Drewnowski A, Kumanyika SK, Glass TA. A systems-oriented multilevel framework for addressing obesity in the 21st century. Prev Chronic Dis. 2009;6(3):A97.

75. Fallon EA, Wilcox S, Ainsworth BE. Correlates of Self-Efficacy for Physical Activity in African American Women. Women Health. 2005;41(3):47-62.

76. $\mathrm{NIH} / \mathrm{NHLBI}$. Clinical Guidelines on the Identification, Evaluation, and Treatment of Overweight and Obesity in Adults-The Evidence Report. Obes Res. 1998;6:51S-209S.

77. Gerber BS, Stolley MR, Thompson AL, Sharp LK, Fitzgibbon ML. Mobile phone text messaging to promote healthy behaviors and weight loss maintenance: a feasibility study. Health Informatics J. 2009;15(1):17-25.

78. Stolley MR, Fitzgibbon ML, Schiffer L, Sharp LK, Singh V, Van Horn L, et al. Obesity Reduction Black Intervention Trial (ORBIT): six-month results. Obesity. 2009;17(1):100-6.

79. Roy A, Bhaumik DK, Aryal S, Gibbons RD. Sample Size Determination for Hierarchical Longitudinal Designs with Differential Attrition Rates. Biometrics. 2007;63(3):699-707.

80. Hedeker D, Gibbons RD. Longitudinal data analysis. Hoboken, NJ: Wiley; 2006
81. Weathers B, Frances K, Barg A, Collier C, Hughes H. Perceptions of changes in weight among African American breast cancer survivors. PsychoOncology. 2006;15(2):174-9.

82. Fitzgibbon ML, Stolley MR. Environmental changes may be needed for prevention of overweight in minority children. Pediatr Ann. 2004;33(1):45-9.

83. Burdette HL, Whitaker RC. Neighborhood playgrounds, fast food restaurants, and crime: relationships to overweight in low-income preschool children. Prev Med. 2004;38(1):57-63.

84. Ross CE, Mirowsky J. Neighborhood disadvantage, disorder, and health. J Health Soc Behav. 2001;42:258-76.

85. Kong A, Tussing-Humphreys LM, Odoms-Young AM, Stolley MR, Fitzgibbon ML. Systematic review of behavioural interventions with culturally adapted strategies to improve diet and weight outcomes in African American women. Obes Rev. 2014;15 Suppl 4:62-92.

\section{Submit your next manuscript to BioMed Central and we will help you at every step:}

- We accept pre-submission inquiries

- Our selector tool helps you to find the most relevant journal

- We provide round the clock customer support

- Convenient online submission

- Thorough peer review

- Inclusion in PubMed and all major indexing services

- Maximum visibility for your research

Submit your manuscript at www.biomedcentral.com/submit 